
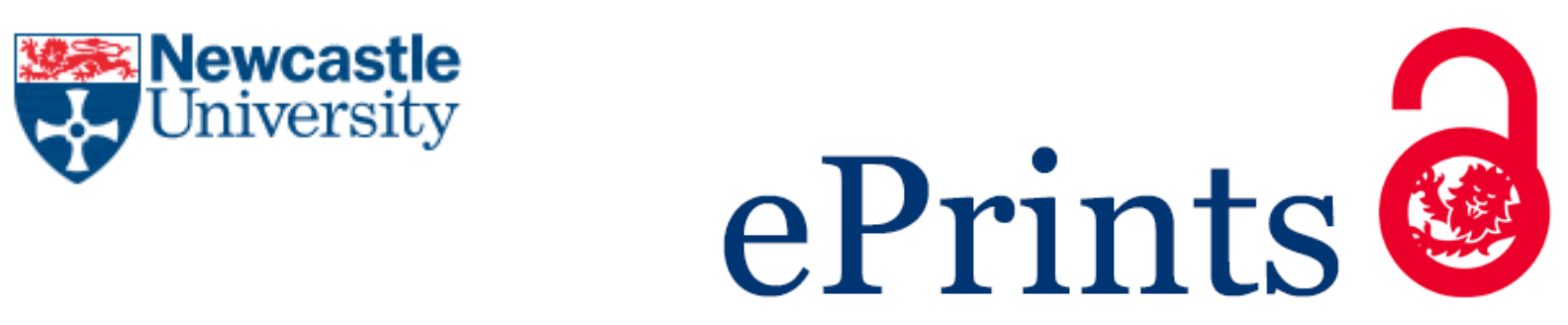

Roskilly AP, Ahmad Al-Nimr M.

Sustainable Thermal Energy Management.

Energy Conversion and Management 2017

DOI: https://doi.org/10.1016/j.enconman.2017.12.018

\title{
Copyright:
}

(C) 2017. This manuscript version is made available under the CC-BY-NC-ND 4.0 license

DOI link to article:

https://doi.org/10.1016/j.enconman.2017.12.018

Date deposited:

$12 / 01 / 2018$

Embargo release date:

19 December 2018

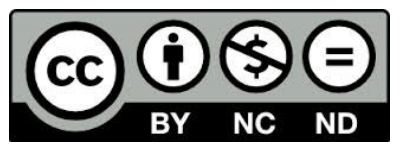

This work is licensed under a

Creative Commons Attribution-NonCommercial-NoDerivatives 4.0 International licence 


\section{Sustainable Thermal Energy Management}

Improving energy efficiency and reducing both energy demand and greenhouse gas emissions are major challenges for civil society. Whilst there is no straightforward answer, research and development (R\&D) in thermal energy management has been continuously attempted to find sustainable solutions. Sustainable Thermal Energy Management International Conferences (SusTEM) were organised in 2010, 2011 and 2015 - each was complemented by a special issue [1-3] to facilitate research dissemination and promote knowledge transfer. In spite of existing endeavours, more R\&D is required to strive for continuous improvement and breakthroughs.

SusTEM2017 took place in the Netherlands on 28-29 June and the scope covered industrial waste heat utilisation; industrial energy, materials and products; renewable heating and cooling systems; building energy performance; control, modelling and optimisation; thermal networks; energy efficiency; economics and policy challenges. In total, 45 studies were orally presented and 23 posters were exhibited - all showcasing important state-of-the-art research being carried out by researchers from the UK, the Netherlands, Italy, Spain, Germany, Austria, Belgium, France, Sweden, Poland, Singapore, China and South Korea. Amongst these studies, 15 are included in this virtual special issue (VSI) whilst the remaining studies are further considered for an upcoming VSI with Applied Thermal Engineering. The 15 articles are summarised in this editorial.

In relation to energy management of the built environment, 6 articles are presented. For fully-glazed buildings, Shen et al [4] propose embedding double windows with pipes and using a ground-source heat exchanger simultaneously to reduce peak heating loads in winter. For buildings connected to district heating networks, Kiluk [5] applies data mining and knowledge discovery based descriptive, machine learning based predictive and prescriptive analytics methods in comparing different tools for energy efficiency supervision. Based on air temperature and solar radiance forecasts, Allison et al [6] develop a load-shifting controller to predict heating requirements of a residential house, pre-charge the under floor heating system and run an air-source heat pump during off-peak periods. Based on experimental results, Peng et al [7] integrate a cooling system with a residential photovoltaic (PV) system and investigate its system performance, environmental impact and payback period. With weather profiles, solar radiance and energy demand data, Ramos et al [8] attempt to address the techno-economic challenges of hybrid PV-thermal systems which integrate heat pumps and absorption refrigeration systems respectively. In the context of the Netherlands, Leeuwen et al [9] present an overview of existing energy supply systems, policies, and options for integrated renewable energy generation of the built environment.

A number of the research articles are related to industrial applications and focus on power generation, energy storage, thermoacoustic engines, waste heat recovery and cooling systems. Using numerical models, Ma et al [10] analyse the power output, energy and exergy efficiencies of half-effect, double-effect and ejector-combined absorption power generation cycles and compare them with the Kalina cycle. To maximise the potential of chemisorption for power generation, Bao et al [11] propose a new resorption cycle which involves multiple expansions using conventional resorption salt pairs. Mahon et al [12] study the potential of using $13 x$ molecular sieves for thermochemical energy storage by conducting experiments with magnesium ions prepared from two impregnation alternatives. By developing numerical models which are validated with experimental data, Wang and Qiu [13] analyse how acoustic characteristics and performance of a four-stage looped thermoacoustic Stirling power generator (which is proposed to generate electricity from $300^{\circ} \mathrm{C}$ waste heat) can be affected by its components, in particular the position of a regenerator and the coupling position of linear alternators. By constructing an experiment rig based on simulation results, Al-Kayiem and Yu [14] propose a new phase tuning method which can effectively adjust the phase angle between pressure oscillations and acoustic velocity to improve the performance of thermoacoustic engines. For an organic Rankine 
cycle, White et al [15] develop a programming optimisation framework and apply it in 3 industrial case studies to identify the optimal working fluids for $150^{\circ} \mathrm{C}$ and $250-350^{\circ} \mathrm{C}$ waste heat sources. By deploying internal shifted fins with optimised size and layout, Fiaschi et al [16] redesign the heat transfer network and heat exchange modules of dryers to improve waste heat recovery in the textile industry. Using modelling with control strategies derived from experiments, Tsamos et al [17] compare the cooling performance, energy consumption, running cost and environmental impact of four $\mathrm{CO}_{2}$ refrigeration system configurations applied to the retail food industry. For lorries used to transport chilled and frozen food, Rai and Tassou [18] estimate the quantity of greenhouse gases emitted by vapour compression and cryogenic refrigeration systems.

This special issue endeavours to highlight state-of-the-art research, which we hope will inspire and contribute to new knowledge in the field.

\section{Acknowledgements}

This special issue was organised by the Thermal Energy Challenge Network funded by the Research Councils UK Energy Programme (EP/P005667/1), with support received from the network stakeholders. We greatly appreciate the commitment made by the authors and researchers involved in reviewing the articles. Their essential contribution safeguards the quality of the research being disseminated. Our special gratitude goes to Dr Janie LingChin, Wendy Taylor and the Elsevier publication team for supporting the organisation of this special issue.

\section{References}

[1] A.P. Roskilly, Y. Wang. Special issue: Sustainable thermal energy management in the process industries conference (SusTEM2010). Applied Energy. 89 (2012) 1-2.

[2] A.P. Roskilly. Special issue: Sustainable thermal energy management in the process industries international conference (SusTEM2011). Applied Thermal Engineering. 53 (2013) 157-9.

[3] A.P. Roskilly, J. Yan. Sustainable thermal energy management. Applied Energy. 186 (2017) 249-50.

[4] C. Shen, X. Li, S. Yan. Numerical study on energy efficiency and economy of a pipeembedded glass envelope directly utilizing ground-source water for heating in diverse climates. Energy Conversion and Management. (2017).

[5] S. Kiluk. Diagnostic information system dynamics in the evaluation of machine learning algorithms for the supervision of energy efficiency of districtheating-supplied buildings. Energy Conversion and Management. (2017).

[6] J. Allison, A. Cowie, S. Galloway, J. Hand, N.J. Kelly, B. Stephen. Simulation, implementation and monitoring of heat pump load shifting using a predictive controller. Energy Conversion and Management. (2017).

[7] Z. Peng, M.R. Herfatmanesh, Y. Liu. Cooled solar PV panels for output energy efficiency optimisation. Energy Conversion and Management. (2017).

[8] A. Ramos, M.A. Chatzopoulou, I. Guarracino, J. Freeman, C.N. Markides. Hybrid photovoltaic-thermal solar systems for combined heating, cooling and power provision in the urban environment. Energy Conversion and Management. (2017).

[9] R.P. van Leeuwen, J.B. de Wit, G.J.M. Smit. Review of urban energy transition in the Netherlands and the role of smart energy management. Energy Conversion and Management. (2017).

[10] Z. Ma, H. Bao, A.P. Roskilly. Principle investigation on advanced absorption power generation cycles. Energy Conversion and Management. (2017). 
[11] H. Bao, Z. Ma, A.P. Roskilly. A chemisorption power generation cycle with multi-stage expansion driven by low grade heat. Energy Conversion and Management. (2017).

[12] D. Mahon, G. Claudio, P.C. Eames. An experimental investigation to assess the potential of using MgSO4 impregnation and Mg2+ ion exchange to enhance the performance of 13X molecular sieves for interseasonal domestic thermochemical energy storage. Energy Conversion and Management. (2017).

[13] K. Wang, L. Qiu. Numerical analysis on a four-stage looped thermoacoustic Stirling power generator for low temperature waste heat. Energy Conversion and Management. (2017).

[14] A. Al-Kayiem, Z. Yu. Using a side-branched volume to tune the acoustic field in a looped-tube travelling-wave thermoacoustic engine with a RC load. Energy Conversion and Management. (2017).

[15] M.T. White, O.A. Oyewunmi, A.J. Haslam, C.N. Markides. Industrial waste-heat recovery through integrated computer-aided working-fluid and ORC system optimisation using SAFT-y Mie. Energy Conversion and Management. (2017).

[16] D. Fiaschi, G. Manfrida, L. Russo, L. Talluri. Improvement of waste heat recuperation on an industrial textile dryer: Redesign of heat exchangers network and components. Energy Conversion and Management. (2017).

[17] K.M. Tsamos, Y.T. Ge, I. Santosa, S.A. Tassou, G. Bianchi, Z. Mylona. Energy analysis of alternative $\mathrm{CO} 2$ refrigeration system configurations for retail food applications in moderate and warm climates. Energy Conversion and Management. (2017).

[18] A. Rai, S.A. Tassou. Environmental impacts of vapour compression and cryogenic transport refrigeration technologies for temperature controlled food distribution. Energy Conversion and Management. (2017).

\author{
Professor Anthony P Roskilly \\ Managing Editor \\ Director of Sir Joseph Swan Centre for Energy Research \\ Newcastle University, UK \\ Email address: tony.roskilly@ncl.ac.uk \\ Professor Mohammad Ahmad Al-Nimr \\ Editor-in-Chief \\ Jordan University of Science and Technology, Irbid, Jordan
}

